\title{
Beyond Being There: \\ Practices that Establish Presence, Engage Students and Influence Intellectual Curiosity in a Structured Online Learning Environment
}

\author{
Janice M. Orcutt \\ The University of the West Indies \\ Laurie P. Dringus \\ Nova Southeastern University
}

\begin{abstract}
To fully understand teaching presence and its implications for the intellectual climate of an online classroom it is necessary to explore the phenomenon from the perspective of the instructors who experience it. Informed by the theoretical perspective of the Community of Inquiry (CoI) model, the actions, intentions and perceptions of instructors were investigated through a collective case study. The goal of this study was to examine the decision processes employed in establishing teaching presence in a structured online environment in order to make a contribution to the body of knowledge from a practical pedagogical perspective. Using the lived experiences of instructors enabled the exploration of the influence pedagogical choices had on the creation of an intellectual climate in the online context. Using semi-structured interviews as the main source of data, the study utilized the Interpretative Phenomenological Analysis (IPA) method as an analytical tool to address concerns of rigor in the qualitative interpretation of experiential data. Results of the collective case revealed student engagement and intellectual curiosity were influenced most greatly by an instructor's active interest and passion for teaching, an ability to identify the relevance of course topics to the student, and the encouragement for a shared responsibility in the learning process. The findings showed that the shared goal of learning extended beyond the stated learning objectives and expected outcomes of a course and served as a foundation in the creation of authentic relationships between instructor and students. In addressing the overarching research question of how instructors establish teaching presence and inspire intellectual curiosity in a structured teaching environment, the findings of this study contribute to knowledge related to the nature of teaching presence and its role in setting an academic climate in an online classroom.
\end{abstract}

Keywords: approaches, effectiveness, online community, graduate, engagement, pedagogy, faculty roles quality instruction, workflow, competencies, scholarship, facilitator, instructor experience, teaching presence

Orcutt, J.M. \& Dringus, L.P. (2017). Beyond being there: Practices that establish presence, engage students and influence intellectual curiosity in a structured online learning environment. Online Learning 21(3), 15-35. doi: 10.24059/olj.v\%vi\%i.1231 


\section{Introduction}

In graduate education, instructors provide intellectual and scholarly leadership by sharing their knowledge, experience and insights as subject matter experts. In this role, they guide students through higher-order learning activities that require critical thinking, synthesis and application of knowledge (Arbaugh, 2013). The presence, availability and supportive nature of the instructor greatly influences the course climate and can generate a positive online learning experience for students (Cox-Davenport, 2014; Kaufmann, Sellnow \& Frisby, 2015). Garrison, Cleveland-Innes, and Fung (2010) suggested that this link between teaching presence and learning depends on the instructor's presence and the role presence plays in establishing and facilitating a climate for discourse and collaboration. The course climate created by an instructor influences the way students learn and the extent to which collaboration is promoted (Cox-Davenport, 2014; Kaufmann et al., 2015).

Teaching presence is the mechanism that bridges the transactional distance between instructor and student in a virtual classroom where direct instruction and facilitation of discourse is achieved through various forms of interaction (Afolabi, 2016; Arbaugh \& Hwang, 2006). Ekmekci (2013) and Bowden (2012) presented arguments of the responsibilities instructors hold in setting academic expectations and ensuring that standards of scholarship are upheld. Instructors can create an academic climate that increases connectedness with students and expectation of scholarship by promoting a shared sense of teaching presence (Afolabi, 2016; Ekmekci, 2013). This sense of "being there" or "being together" is experienced in different ways in the online classroom and must be intentionally created for it to be perceived and felt (Lehman \& Conceição, 2010).

The essence of "presence" is not one-dimensional in that the instructor merely follows a set of prescribed actions that demonstrate availability and supportiveness in the online course. Presence is also a mindset for extending activity between student, instructor and content beyond just being there. The presence mindset includes a strategic workflow of effective practices that lead to co-construction of the intellectual climate shared by the instructor and students in the online course. The present study draws insights from the experience and perspectives of successful online instructors to illustrate how this is achieved in a structured online learning environment.

\section{Background}

Growing pressures persist for higher education to be accountable for the achievement of learning outcomes and retention. Educators are increasingly interested in improving pedagogical strategies by implementing practices that are effective in producing student outcomes in the online environment (Ekmekci, 2013). Shea, Vickers, and Hayes (2010) recognized the importance of advancing the practice of teaching in the online environment through the systematic exploration of pedagogies employed by instructors, and recommended further study into the intentional efforts of instructors in establishing their teaching presence. For distinct pedagogies to emerge, the nature of teaching presence, the transformation of the practices instructors engage in, and the competencies required to perform the tasks of the instructor must be understood (Baran, Correia, \& Thompson, 2013).

Shea et al. (2010) suggested the importance of investigating the intentional efforts instructors undertake in establishing teaching presence, particularly when and where they focus effort, in order to understand its significance to the practitioner. Pedagogical suggestions by researchers over the past decade as reported by Junk, Deringer, and Junk (2011) typically rely on 
conventional practices of interaction, such as participating in discussions or holding online office hours, in the attempt to engage students as a means to achieve expected learning outcomes.

The evolution of the online technologies supporting online educational platforms has enabled interaction among instructors and students to shift from individual approaches to forms of collaborative learning (Garrison \& Akyol, 2013). As this transformation has taken place technologically, the importance of teaching presence and its influence on the learning process has increased in visibility (Arbaugh, 2013). However, as the online teaching environment has advanced, instructors have not always kept pace, showing a tendency to either rely too heavily on technology to form connections with their students or to revert to conventional practices that are more suitable for physical classrooms (Baran et al., 2013; Cho \& Kim, 2013; March \& Lee, 2016). Those who are new to online environments are challenged with finding suitable approaches to teaching in virtual classrooms because many did not learn that way themselves (Niess \& GillowWiles, 2013).

\section{Focus of the Study}

The study focuses on the need to understand the nature of teaching presence from an instructor's perspective and the implications of this on establishing an intellectual climate in the online classroom. The essences of teaching presence that emerge in structured online environments are unknown. While the course content is prescribed for the instructor in the structured online course, the instructor's role to inspire intellectual curiosity is not. What inspires instructors to reach beyond prescribed pedagogies and competencies that are related to teaching presence is the central focus of the study.

The Community of Inquiry (CoI) theoretical model introduced by Garrison, Anderson and Archer (1999) provides a conceptual framework for studying the online learning experience. Research related to teaching presence has had a primary focus of verifying the existence of the construct of teaching presence through text analysis of interactions (Garrison \& Arbaugh, 2007). The empirical information gathered from these studies has not provided a full understanding of the experience of online instructors (Shea et al., 2010; Kidder, 2015) nor has it provided substantial guidance to instructors on how to effectively create a teaching presence that establishes a productive and efficient course climate (Duncan \& Barnett, 2010), particularly when the course is designed to follow a structured and prescribed approach to the content and to delivery.

Using a collective case study approach, the experiences of online instructors were explored to ascertain the nature of teaching presence in a specific online context and gain insight on how pedagogical choices might influence the establishment of an intellectual climate appropriate to the course offering. While the phenomenon of an intellectual climate exists in both online and traditional classrooms, it is only by examining the experiences, decisions and actions of online instructors as done in this study, that an understanding of an instructor's role in establishing such a climate in the online context could be gained. A qualitative approach allowed for the in-depth exploration of instructor's experiences, intentions and perceptions as they related to establishing their presence within an online environment (Creswell, 2013).

This study utilized the teaching environment of a selected university where classes are delivered in an online environment typical of for-profit institutions, whereby course materials and learning activities follow a standardized delivery pattern independent of course content. In the standardized delivery format of the research site, all eight-week courses were designed within four two-week teaching modules. All course activities were pre-developed by a course committee 
composed of instructors with industry expertise. Instructors were expected to follow the format without deviation and were not allowed to change assignments or content without approval of the committee. This course environment created a common context across all instructors in which the actions, intentions and choices of selected instructors could be isolated and examined. As a result, through the interviews about the approaches used in establishing presence in the confines of this structure, it was revealed what these instructors perceived as most important in establishing their presence and the connection with their students.

Through this study, the researchers sought to qualitatively assess the processes utilized by instructors when establishing teaching presence in order to provide insight into its influence on the creation of an intellectual climate within the online classroom (Cox-Davenport, 2010; Duncan \& Barnett, 2010). The themes that emerged from the detailed examination and analysis of the experiences of the selected instructors when establishing teaching presence in a structured course environment provided a vocabulary with which to describe the shared pedagogies of instructors and served to catalog, from a temporal perspective, commonalities in actions and intent associated with setting an intellectual climate. As suggested by Shea et al. (2010), this exploration allowed for discovery of how the intentional efforts of these instructors may be linked to the intellectual climate of their classes and its influences on the learning process that enabled the collaborative or independent progress toward knowledge construction.

While the course content is prescribed for the instructor in the structured online course, the instructor's role to inspire intellectual curiosity is not prescribed. Discovering what inspired instructors to reach beyond prescribed pedagogies when establishing teaching presence was a primary goal of this study, seeking explanations or answers to questions such as: How do instructors perceive their own teaching presence practices? What does teaching presence mean to them? What practices do instructors rely on to inspire intellectual curiosity of students that reach 'beyond being there' in an online environment?

\section{Literature Review}

Teaching presence is a phenomenon that exists in both physical and virtual classrooms; however, in the online learning environment teaching presence increases in importance as it provides a vital link to students who are separated by time and space from their instructors (Afolabi, 2016; Arbaugh \& Hwang, 2006). The Community of Inquiry (CoI) model introduced by Garrison et al. (1999) provides a conceptual framework within which teaching presence can be seen to influence the social and cognitive processes that occur in online learning environments. As a theoretical model, the $\mathrm{CoI}$ defines the existence of teaching presence through the interaction that occurs between students and instructors primarily during the functions of direct instruction and facilitation of discourse. As investigations into teaching presence have evolved, the understanding

of the collaborative nature of the online environment has increased and provided insight into the shared agency of the learning process (Bawa, 2016; Shea \& Bidjerano, 2010). However, the role of the instructor and the necessity of the instructor's presence in the classroom to set academic expectations and inspire intellectual curiosity are critical to supporting scholarly achievement (Bowden, 2012; Ekmecki, 2013). 


\section{CoI Model}

Garrison et al. (1999) described e-learning in the context of a community of learners who are not bound by time or place, as with traditional classroom instruction, but who relied on computer-mediated interaction to facilitate the process of learning. Interaction in the online learning environment, not only involves the exchange of information intended to increase or reinforce knowledge development within the context of the course, it also actively encourages dialogue which leads to individual knowledge construction (Bondi, Daher, Holland, Smith, \& Dam, 2016). Garrison et al. (1999, 2001) argued that it is through this interaction that a community of learning is created and sustained, and that it is within the "community of inquiry" that critical thinking is developed and learning results. It was from these foundations that the Community of Inquiry (CoI) model was formulated. This theoretical model has been prominent in online education research for the past decade.

The Community of Inquiry (CoI) model relies on the assumption that learning occurs as a function of three primary and interdependent elements: social presence, cognitive presence, and teaching presence. It is an assumption of the model that the interactions among the three forms of presence result in the establishment of a community of inquiry in which critical thinking can develop and thrive (Arbaugh, 2013). The model identifies teaching presence as a complex construct which bridges the transactional distance between instructor and student through interaction and creates an environment within which social and cognitive processes can occur (Arbaugh \& Hwang, 2006; Garrison et al., 2010; Yang, Quadir, Chen, \& Miao, 2016).

Integral to the CoI model is the presumed interrelationship among the three core constructs. Graphically represented by three intersecting circles, the CoI model identifies the overlap and interdependence of the three elements (Garrison \& Arbaugh, 2007). At the intersection of these core constructs are three functions identified by the authors and presumed to be carried out primarily by the instructor to ensure a meaningful and successful educational experience. These functions of selecting content, supporting discourse, and setting climate are used as indicators of each presence and represent how the instructor creates the presences identified in the model (Garrison et al., 2001).

\section{Teaching Presence}

The element of teaching presence has emerged as an integral part of the model with respect to its relationship with the other two elements and its influence on student satisfaction, perceived learning and sense of community (Joo, Joung, \& Kim, 2013; Southcombe, Fulop, Carter, \& Cavanagh, 2015). Teaching presence is the "binding agent" which directs the educational purposes for the community of learners (Garrison et al., 1999). While the authors suggested that any of the participants in the community of inquiry could participate in creating teaching presence, they noted that these activities fell primarily in the responsibilities of the instructor.

The indicator categories for teaching presence have evolved since the time this original description was proffered, however, facilitation of discourse and direct instruction are considered to be the key indicators of teaching presence during the examination of an active course environment (Garrison \& Arbaugh, 2007). Both indicators focus on instructor involvement within a course, and refer to the relevance of instructor interaction with students in the context of the course but differentiate between student-led and instructor-led interaction respectively. 


\section{Setting Climate}

Setting climate is identified in the CoI model as a function primarily performed by the instructor which is used in establishing a productive learning environment. While selecting content and supporting discourse have been the focus of studies related to the construct of teaching presence, little has been investigated with respect to the function of setting climate and its role in establishing teaching presence.

A few recent studies have indicated the importance of the learning climate, such as the study conducted by Brock and Abel (2012) that found instructors' actions to be a significant element in creating an environment for high-level learning. However, an exploratory study by Cox-Davenport (2010) appears to be the first to investigate the climate setting function as a method of instruction used during the establishment of teaching presence within the online environment. Using a grounded theory approach, Cox-Davenport identified characteristics of activities and strategies employed by instructors while establishing their teaching presence as "climate factors". She examined which climate factors were specifically employed by instructors when setting a climate of open communication and then exploring the perceived effect of those climate factors on the development of social presence within their online courses. Cox-Davenport's findings suggested that the level of influence the instructor exerts over the creation of the educational environment in the online classroom can be attributed to strategies which enhance social presence and enable student participation.

\section{The Nature of Teaching Presence}

Teaching presence has a significant effect on learning persistence and is highly related to the level of learning that occurs within an online course (Joo et al., 2013). The collaborative construction of knowledge that occurs as a result of the interaction within an online environment does not just happen, but requires the intentional and responsive intervention of an instructor (Xin, 2012). Active interaction in an online course is not automatic and requires skillful intervention by an instructor to promote a level of cognition that can become self-regulated (Cho \& Kim, 2013). This is particularly important in graduate level education, where expectations of academic rigor and achievement are greater (Bowden, 2012).

It is evident that the level of presence and degree of visible involvement demonstrated by the instructor is dependent upon the teaching strategy and personal preferences of the instructor (Ravenna, 2012). However, it is also evident that the level of teaching presence can dramatically influence the quality of facilitation that leads to successful learning in asynchronous environments (Costley, 2015; Hung \& Chou, 2015; Rovai, 2007). A key step in the achievement of academic expectations and scholarship is the role the instructor plays in setting the academic climate for such performance (Bowden, 2012; Ekmekci, 2013). However, there is little guidance for practitioners with respect to fulfilling this vital function related to cognitive achievement.

Instructors who are used to the immediacy of feedback and interaction experienced in faceto-face environments are concerned about how they can achieve similar outcomes in the online environment (Costley, 2015; Hung \& Chou, 2015). These instructors, who are comfortable with the knowledge of how to project their presence in a physical classroom, are struggling with how to do so in a virtual environment (Baran et al., 2013; Duncan \& Barnett, 2010). Baran et al. (2013) contended that change in pedagogy is needed, and that successful instructors could share insight, transfer knowledge, and explain intentions critical to practices used while teaching online. They 
identified the need for further research on how instructors create their online persona, or presence, with examination of the practices, perspectives, and assumptions that support their online role.

\section{Approach}

\section{Method}

The case study as a research method is favored by interpretivists due to its holistic treatment of the subject phenomenon in a natural setting (Willis, 2008). The collective case study represents a repetitive application of procedures to each case selected, whereby each case selected is purposefully chosen within a bounded system to represent different perspectives of the issue being investigated (Creswell, 2013). At the research site, instructors adhered to a structured approach to course delivery whereby course design included the same components (e.g., lecture slides, discussion questions, homework assignments, research projects, and synchronous "whiteboard" sessions) following a predefined schedule each term. Analysis of faculty evaluations revealed differences in student responses associated with the construct of teaching presence such as facilitating discussions and timely and regular feedback. Conceptual questions drawn from the circumstances of the research environment helped shape the curiosity of the researcher (Stake, 1995). In particular, the variation in student reports of instructor contribution to learning created an interest in understanding differences in instructional practices within an otherwise tightly constrained online environment. This led to the formulation of a central question that created a conceptual structure for organizing the study of this case (Stake, 1995): RQ1: In a structured online environment, how do instructors establish teaching presence and inspire intellectual curiosity within the courses they teach?

This conceptual question was expanded to incorporate the instructor's point of view, using sub-questions that highlight specific areas addressing the goals of this study: RQ2: What practices do instructors choose to employ when establishing teaching presence? RQ3: What are the intentions of instructors when determining which strategies will best help them establish teaching presence? RQ4: How do instructors perceive their decisions and practices relative to teaching presence and its influence on the intellectual climate in the classroom?

Teaching presence and the process of establishing presence within an online environment can be a complex and subtle activity undertaken by an instructor (Anderson \& Dron, 2011). Qualitative research provides a means of exploring the phenomenon of teaching presence from the instructor's point of view, allowing for in-depth discovery through an interpretive lens (Friesen, 2009). A case study approach was selected for this exploration of the phenomenon of teaching presence due to its ability to help develop an in-depth understanding of the practices (how) and intentions (why) of the instructors (Yin, 2014).

Utilizing a case study approach, the research questions were addressed as the participants revealed what teaching presence meant to them and described the processes they adopted to establish presence in their online classrooms. This collective case study provided a context specific exploration of the topic, allowing the researcher to draw cross-case conclusions that highlight commonalities among the individual instructors interviewed, strengthening the findings of the study (Yin, 2014). To provide a more rigorous approach to analysis, an experiential qualitative method called Interpretative Phenomenological Analysis (IPA) developed by Smith, Flowers, and Larkin (2009) was used as a means to increase the credibility of the study's findings. 


\section{Boundaries of the Case}

Binding the case helped ensure the study remained within a reasonable scope (Baxter \& Jack, 2008). Defining the boundaries of this case relied on setting selection criteria that made it possible to identify instructors who were seemingly more effective at creating a successful learning environment than their counterparts, specifically as it applied to contributing to learning and facilitating learning activities. Utilizing student evaluation data supplied from the research site helped accomplish this, with the general boundaries of the case originally defined as: (1) instructors employed during a defined period (2010 - 2012); (2) instructors rated highly in their contribution to learning, and (3) instructors rated highly in facilitating learning activities (e.g., discussion thread participation). Instructors who fell outside the boundaries of the case were not eligible to be participants.

\section{Participant Selection}

Purposeful sampling is typically employed in case study to utilize a group of people who can best inform the researcher about the research problem, rather than securing a probability sample which enables statistical inferences to a population (Creswell, 2013). Achieving homogeneity in the sample cases was an objective of the participant selection process for this study, as the intent of the study was to draw from the experiences and insights of successful instructors. The shared experience of working within the same structured academic program at the specific school provided the first level of homogeneity in the sample. Homogeneity for the purposes of this study was also measured from the ratings of instructors in the criteria identified as boundaries of the case that served as selection criteria, similar to the study conducted by Baran et al. (2013). An average performance score from student evaluations was calculated using the institution's values as the criteria for success to determine the final set of eligible participants in the study. The analysis essentially confirmed six candidates as strong subjects for the study, revealing their exceptional performance across all categories of evaluation, exceeding the average performance score in each category evaluated. As a result of this final analysis, the group of instructors selected for the collective case study were assigned pseudonyms: Davina, Dominik, Karissa, Leighton, Pavia, and Yosef. The two instructors selected as potential pilot case study subjects were Ludwig and Simon.

\section{Data Collection}

Data collection in case study research is extensive and draws from multiple sources of information for the purposes of data accuracy, validity and reliability (Yin, 2014). In-depth semistructured interviews were used as the primary source of data. However, student evaluation data provided by the institution were used to produce convergent evidence of the activities reported by the instructors in the interviews and served as a means of triangulation, providing support for the accuracy and interpretation of the information collected (Stake, 2006).

The in-depth interview techniques used in data collection supported the exploration of instructor's intentions, actions, and perceptions when establishing their presence in the online course environment. The goal of the semi-structured interview in this study was to elicit meaningful and descriptive first-person accounts of the experiences and intentions of the participants (Smith et al., 2009). Following an interview approach recommended by Seidman (2006) the in-depth phenomenological interviews were conducted in three distinct parts exploring in sequence: (1) their personal history related to online education, (2) their experiences as online instructors, and (3) reflection on the meaning of their experiences. 


\section{Data Analysis}

Case study research has not been codified, and as a result, the rigor of analysis performed has been the subject of scrutiny even though it is recognized as a distinctive form of empirical research (Yin, 2014). Due to this concern for rigor, a structured approach to the analysis of the qualitative data is often sought. Interpretative Phenomenological Analysis (IPA), a method introduced in the mid-1990s to understand experiences of particular groups of people within specific socio-cultural contexts, was identified as the analytical method used for this study. IPA provides a process to analyze qualitative data when seeking to understand the first-person perspective of lived experiences from the third person position (Smith et al., 2009).

Interpretative Phenomenological Analysis (IPA) is an experiential qualitative research method that provides a systematic approach to interpreting first person accounts of experiences (Smith et al., 2009). This approach is not a predictive evaluation tool, but rather a pragmatic method used to describe, explain and interpret patterns and themes that emerge from the narratives resulting from in-depth interviews. Following the IPA protocol, the researcher individually analyzed each case thoroughly prior to performing the cross-case analysis. For each case the researcher completed the following five steps of the IPA method as outlined by Smith et al. (2009): (1) reading and re-reading interview transcripts, (2) initial noting comprised of an exhaustive three part procedure of commenting which includes (a) descriptive interpretation, (b) observation of linguistic usage, and (c) notation of conceptual questions that arise during interpretation, (3) development of emergent themes, (4) identification of connections across emergent themes, and (5) bracketing and journaling personal reflections before moving to the next case.

During the process of content analysis, the researcher was challenged to transform the data collected for each case into informational codes that helped categorize the data (Chenail, 2012). The NVivo software provided the researcher with substantial capability in performing this step of the protocol. By importing the notated transcript files from the three interview sessions for each case independently, the source data could be categorized using the node functionality within the software. Following the IPA method, the comments and notes were methodically analyzed to produce a set of themes or nodes in chronological order, based on how they emerged in the interview.

The final stage of analysis in a collective case is to look for patterns of themes across cases. The approach of analysis suggested in the IPA method is to align the themes of each case in a tabular fashion to visually identify recurrent or major themes across cases (Smith, et al., 2009). Using this approach to analysis, a theme was required to have been present in the results of more than half of the cases, or four out of the six subject cases, in order to be considered recurrent. The first author utilized the data collected from the six subject cases for the analysis of the collective case. In addition to looking for points of convergence and commonality in themes, this step of analysis also allowed the researcher to identify areas of divergence and individuality. It is from this final analysis the findings of the study are derived and the final report was produced. 


\section{Results}

The first author utilized the data collected from the six subject cases for the analysis of the collective case, providing a view of the collective case as a singular entity, rather than a compilation of individual reports. The results for the collective case were compiled to report patterns in narrative themes and identification of recurrent themes related to practices and intentions associated with establishing presence. While each of the participants' personal accounts are highly individual, there were themes in responses that were identified from the narrative summaries.

Using temporal references to associate specific actions to the phases of course delivery, the collective case analysis revealed the similarities and differences among the individual activities undertaken by the six subjects when establishing teaching presence. The tabulation method of identifying patterns across cases confirmed the recurrent actions reported at a collective level and are displayed in Table 1. Of the recurrent actions identified, those unanimously reported by all participants were considered as primary actions taken while establishing presence and annotated as PRI in Table 1.

\begin{tabular}{|c|c|c|c|c|c|c|c|}
\hline & Davina & Dominik & Karissa & Leighton & Pavia & Yosef & Recurrent \\
\hline \multicolumn{8}{|c|}{ Actions in Preparation for Course } \\
\hline Content Review & Yes & Yes & Yes & Yes & Yes & Yes & Yes (6) PRI \\
\hline $\begin{array}{l}\text { Develop Instructional } \\
\text { Plan }\end{array}$ & Yes & Yes & Yes & Yes & Yes & Yes & Yes (6) PRI \\
\hline Topic Familiarization & Yes & Yes & Yes & Yes & & Yes & Yes (5) \\
\hline $\begin{array}{l}\text { Supplement Course } \\
\text { Material }\end{array}$ & Yes & Yes & & Yes & & Yes & Yes (4) \\
\hline $\begin{array}{l}\text { Check Course } \\
\text { Schedules }\end{array}$ & Yes & & & Yes & Yes & Yes & Yes (4) \\
\hline Check Technology & Yes & & Yes & Yes & Yes & & Yes (4) \\
\hline \multicolumn{8}{|l|}{ Actions in Preview Period } \\
\hline $\begin{array}{l}\text { Form Authentic } \\
\text { Relationships }\end{array}$ & Yes & Yes & Yes & Yes & Yes & Yes & Yes (6) PRI \\
\hline $\begin{array}{l}\text { Send/Post Welcome } \\
\text { Letter }\end{array}$ & Yes & Yes & Yes & Yes & Yes & Yes & Yes (6) PRI \\
\hline Initiate Interactions & Yes & Yes & & Yes & Yes & Yes & Yes (5) \\
\hline $\begin{array}{l}\text { Note Attendance and } \\
\text { Participation }\end{array}$ & Yes & Yes & Yes & & Yes & & Yes (4) \\
\hline Post Announcements & Yes & & Yes & Yes & Yes & & Yes (4) \\
\hline Build Rapport & Yes & Yes & & Yes & & Yes & Yes (4) \\
\hline $\begin{array}{l}\text { Available for Support / } \\
\text { Assistance }\end{array}$ & & Yes & Yes & Yes & & Yes & Yes (4) \\
\hline \multicolumn{8}{|c|}{ Actions During First Week } \\
\hline $\begin{array}{l}\text { Available for Support / } \\
\text { Assistance }\end{array}$ & Yes & Yes & Yes & Yes & Yes & Yes & Yes (6) PRI \\
\hline Initiate Interactions & Yes & Yes & Yes & Yes & Yes & Yes & Yes (6) PRI \\
\hline Set Expectations & Yes & Yes & Yes & & Yes & Yes & Yes (5) \\
\hline Build Rapport & & Yes & Yes & Yes & Yes & Yes & Yes (5) \\
\hline $\begin{array}{l}\text { Shared Responsibility } \\
\text { for Learning }\end{array}$ & & Yes & Yes & Yes & & Yes & Yes (4) \\
\hline $\begin{array}{l}\text { Note Attendance and } \\
\text { Participation }\end{array}$ & Yes & & Yes & Yes & Yes & & Yes (4) \\
\hline
\end{tabular}

Table 1. Collective Case: Recurrent Themes in Establishing Teaching Presence (Temporal Context) 


\begin{tabular}{|c|c|c|c|c|c|c|c|}
\hline \multicolumn{8}{|c|}{ Actions in Remaining Weeks } \\
\hline $\begin{array}{l}\text { Available for Support / } \\
\text { Assistance }\end{array}$ & Yes & Yes & Yes & Yes & Yes & Yes & Yes (6) PRI \\
\hline Facilitate Discourse & Yes & Yes & Yes & Yes & Yes & Yes & Yes (6) PRI \\
\hline $\begin{array}{l}\text { Provide Substantive and } \\
\text { Constructive Feedback }\end{array}$ & Yes & Yes & Yes & Yes & Yes & Yes & Yes (6) PRI \\
\hline Reinforce Expectations & Yes & Yes & Yes & Yes & Yes & Yes & Yes (6) PRI \\
\hline Post Announcements & Yes & & Yes & & Yes & Yes & Yes (4) \\
\hline $\begin{array}{l}\text { Shared Responsibility } \\
\text { for Learning }\end{array}$ & & Yes & Yes & Yes & & Yes & Yes (4) \\
\hline
\end{tabular}

Table 1 (cont). Collective Case: Recurrent Themes in Establishing Teaching Presence (Temporal Context)

*PRI denotes primary action

A visual representation was constructed to provide a contextualized understanding of the sequence of actions taken to establish presence within the temporal framework of the course. Figure 1 provides this representation, showing those themes (shaded) that were considered primary actions (PRI) for each of the phases of course delivery.

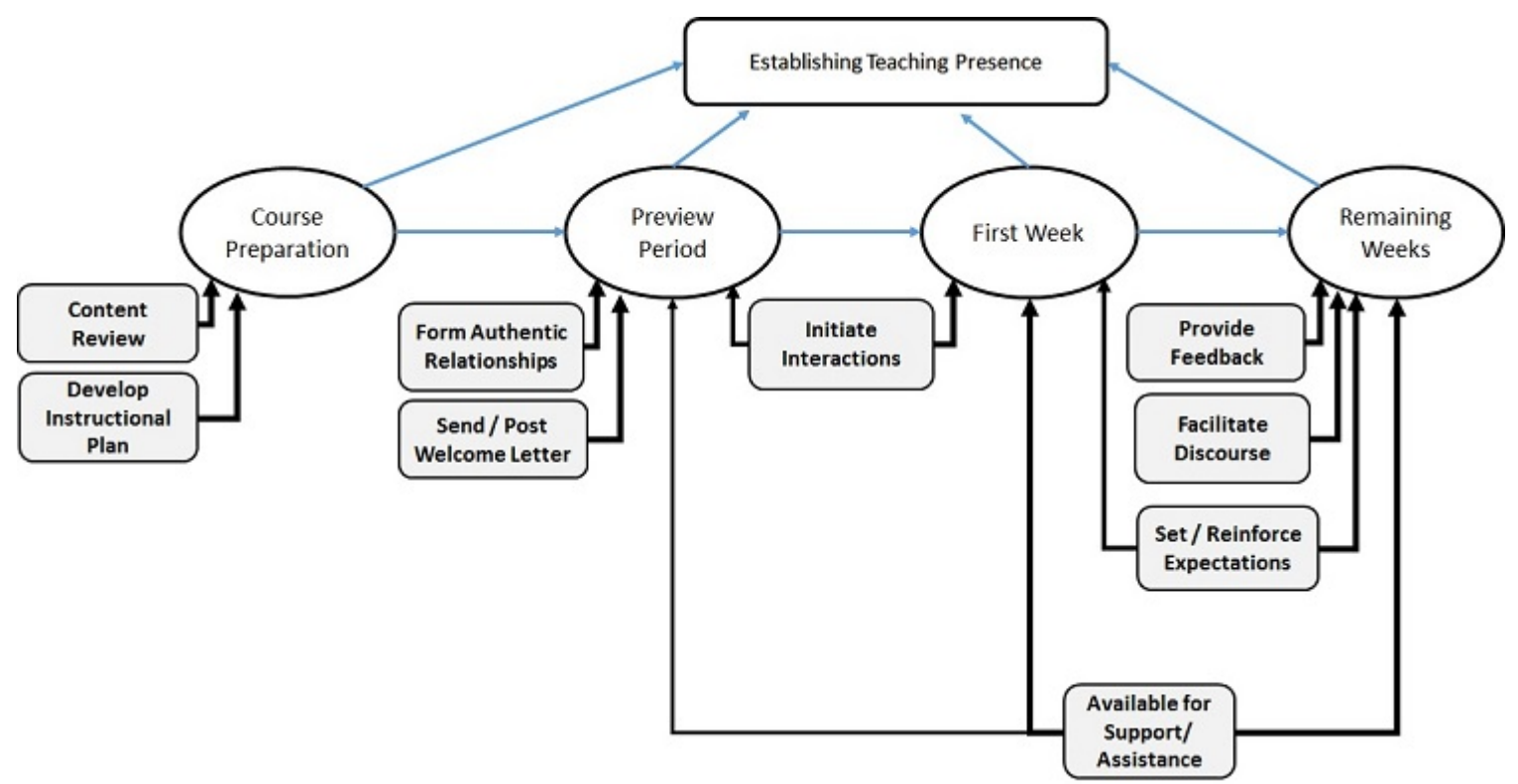

Figure 1. Contextual representation of primary actions (PRI) in establishing teaching presence.

The interviews provided insight with respect to the intentions of the instructors as they revealed the reasons behind the actions taken when establishing teaching presence. For example, the following are excerpts of quotes by instructors (as presented in Orcutt, 2016):

Participant Dominik (instructor) “... to establish a relationship with the students, respect the students, respect the fact that they may know things, about things that you the instructor don't know that can be helpful in the class, and that the instructor can walk away with some insight that they had not considered. But to me the biggest thing is to respect the students. Don't try to be the overbearing authority." (Orcutt, 2016, p.120). 
Participant Leighton (instructor)“... it's trying to get to know the student, get to know their work life experiences ... the other thing that I emphasize is that the connection I have with the students is more than the four modules that we're together, I really want to know this person, I really want to as a professional stay in touch and continue to help in ways that would benefit their career..."(Orcutt, 2016, p.151).

The analysis of the collective case revealed three primary intentions as recurrent themes underlying the actions of the instructors: (a) to ensure engagement and interaction that supported learning, (b) to connect with students in authentic ways, and (c) to serve as a resource to share experiences and knowledge that guides learning.

To understand which of the actions of instructors supported and fulfilled these intentions, a cluster analysis based on word similarity within the themes was performed with the merged data to identify relationships between the actions taken in establishing presence and the identified intentions. Figure 2 provides a visual representation of the results. Only those actions showing a coefficient value of .80 or greater are depicted in the representation, to provide greater clarity in understanding the primary actions associated with fulfilling instructors' intentions. As depicted in Figure 2, the identification of three key actions most greatly related to fulfilling all three intentions also emerged from this analysis: forming authentic relationships with students, building rapport, and setting and reinforcing expectations. Using the Pearson correlation coefficient generated from the cluster analysis as a measure of the relationship between the actions and the intentions, it was determined that overall instructors' actions in establishing presence most greatly supported the intention of ensuring engagement and interaction that supported learning $(r=.955)$.

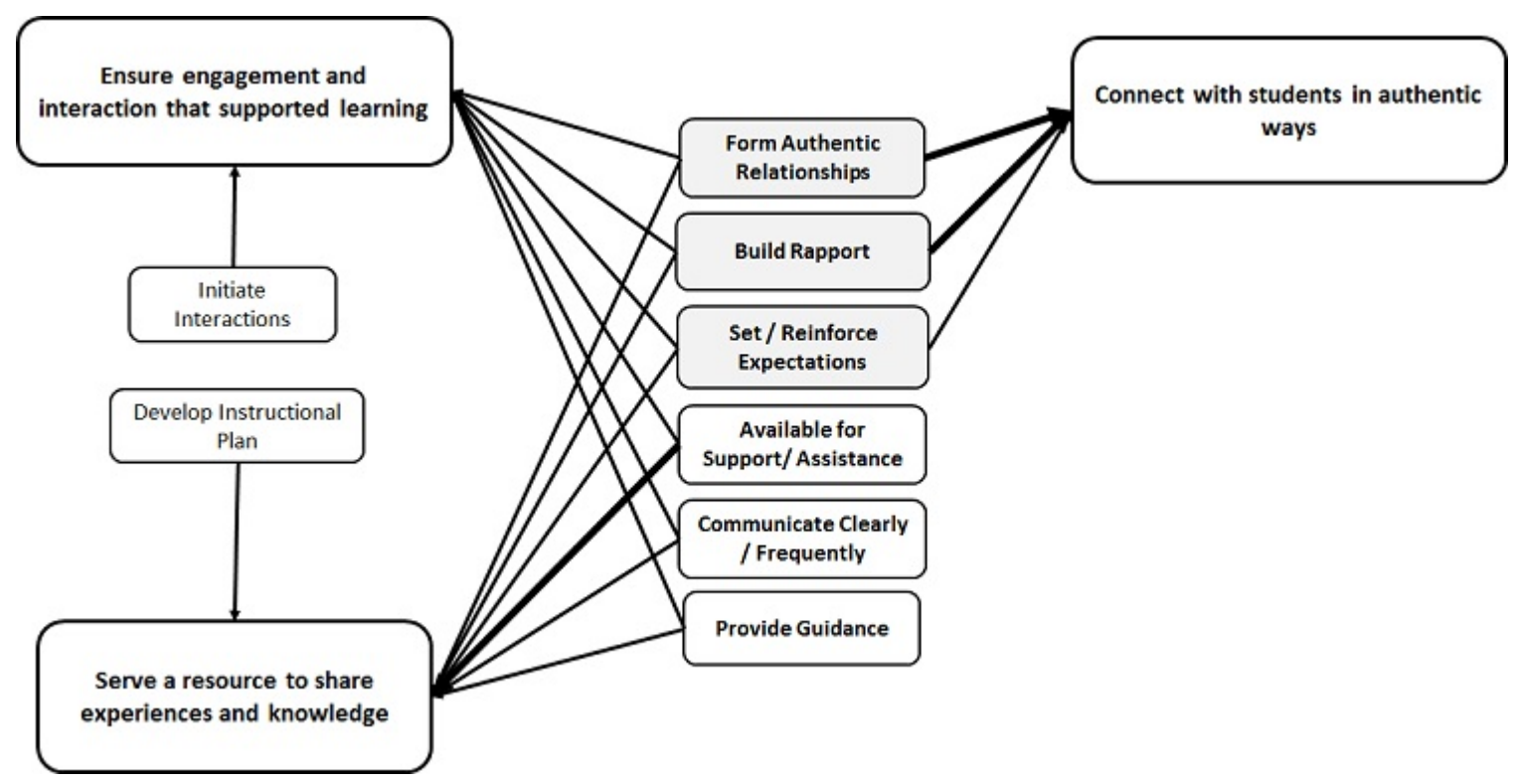

Figure 2. Recurrent themes in intentions related to practices establishing teaching presence.

Further exploration of the collective case was conducted with respect to those practices identified as related to setting the academic tone of courses and inspiring intellectual curiosity of students. Although a number of themes were associated with setting the academic climate, the 
primary recurrent theme that emerged from analysis of the merged results was setting and reinforcing expectations.

Participant Davina (instructor): "Let's face it, the subject can be boring if you don't bring any positive energy to it, so being creative in terms of how you set the tone in your class room ... let the class know what you expect of them, in the very beginning be present in the module discussions so you get a clear understanding of what types of students you have, so you can help to guide them as they move forward ..." (Orcutt, 2016, p.105).

Participant Dominik (instructor): "The academic tone is generally directed at getting students to think out of the box ... bringing out critical thinking instead of just marketing talk ... it's trying to get the students to think originally, using research literature sources for information and not just trade press. ... it's encouraging the students to look at the research slash academic or scholarly literature about what's going on in the field that may be in the laboratory but not in the office yet" (Orcutt, 2016, p.120).

Figure 3 provides a visual representation of these recurrent themes and relationships that emerged during this analysis of the actions related to setting academic climate and inspiring intellectual climate.

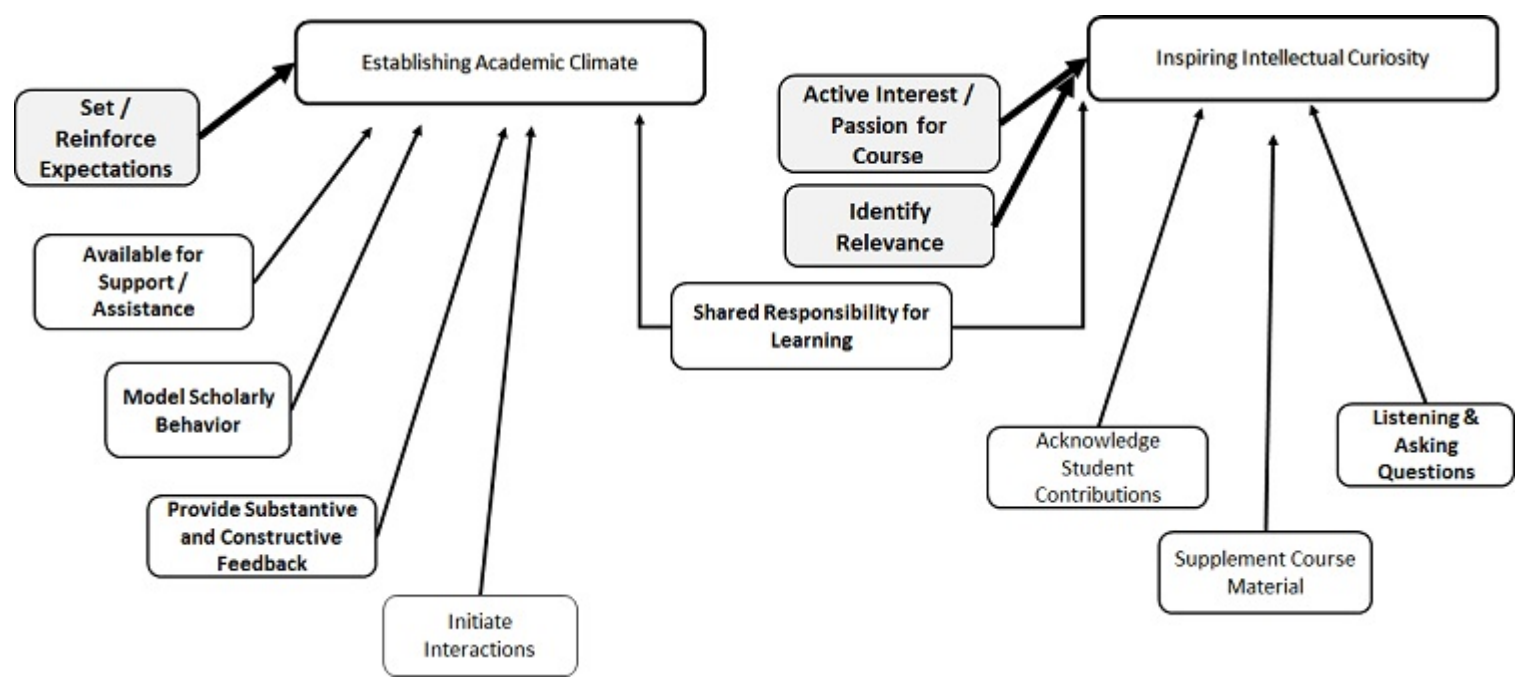

Figure 3. Recurrent themes related to setting intellectual climate.

The analysis relating to inspiring intellectual curiosity resulted in the identification of two primary recurring themes: showing an active interest or passion for the course and identifying relevance of the course for students. The collaborative atmosphere created by promoting a shared responsibility in the learning process in the classroom had an influence on both academic functions and was demonstrated mostly through acknowledging students contributions.

Participant Dominik (instructor): "One of the things that I tell students at the very beginning is that there may be areas in the course where any particular student is more knowledgeable than anybody else in the course and has relevant experience that can be shared and should be shared to allow everybody to take advantage of that" (Orcutt, 2016, p.120). 


\section{Meaning of Teaching Presence}

\section{Discussion}

Of importance to the study was the meaning "teaching presence" held for instructors. To support the determination of whether a consistent meaning of teaching presence was shared by the participants, descriptors were used in interpreting their responses related to what teaching presence meant to them. A single recurrent theme was expressed in the participants' perception of what teaching presence meant to them: the articulation of teaching presence in the terms of responsiveness to students' needs and expectations. The perspective of teaching presence offered in the collective case is indicative of the instructors' recognition that responding to needs and expectations of students establishes that environment of trust which precipitates the formation of a community of learning where teaching presence is experienced (Cox-Davenport, 2010; Kaufmann et al., 2015). This suggests a high degree of student-centeredness in the instructors, recognizing the supportive nature of the role in which they serve and how essential it is to the cohesion of the learning group. Although in the Community of Inquiry (CoI) model teaching presence is defined in terms of facilitation of discourse and direct instruction, this interpretation reflects the close relationship teaching presence has with social presence while it is being established in the online classroom.

\section{Practices in Establishing Presence}

Within the temporal context of course delivery, the study identified four phases of delivery that served to reference the sequence of activities undertaken by instructors when establishing their presence in the online classroom: (1) course preparation, (2) preview period, (3) first week of instruction, and (4) remaining weeks. Of these four phases, the first three are associated with establishing presence, while the last is associated with maintaining presence.

Across the interviews, instructors exhibited a different tone while describing the initial activities when establishing presence whereby the instructors conveyed a common belief that they had to proactively initiate the interaction with students, possibly before the student even logged in for the first time. During the course preparation period prior to students having access to their online courses, the primary actions taken by instructors were to perform a thorough content review and develop an instructional plan. In this way, instructors conveyed their personality in the course content providing a sense of presence when they were not physically online with students. When students were provided access to their courses, during the preview period, the initial action commonly taken by instructors was to send or post a welcome message that communicated more than logistical aspects of the course, providing an introduction to the human qualities of the instructor. This form of personal disclosure provided a means to find connections with students upon which authentic relationships could be formed. However, the outreach to students extended beyond the welcome email, indicating a differentiation exists in mindset as well as action from common practices.

The analysis of the collective case revealed that after the initial interaction through the welcoming post, all instructors took a proactive stance during the first week of the course by initiating interactions with students, rather than waiting to respond to actions taken by students. This outreach to students not only confirmed instructors' availability to provide support and assistance, but also communicated a direct interest in the student being an active participant in the learning process. 
Although this study focused on the actions related to establishing teaching presence, which predominantly involved the actions taken at the beginning of a course, there were commonalities that were conveyed about the remaining weeks related to maintaining a presence in forums. A common activity in all online instruction is the instructor's engagement of students in the discussion forums by posting responses and facilitating the interaction among students.

A notable difference was observed in the way the instructors described their interaction with students in the forums. Most described it as more than "posting to forums" indicating a desire to help students gain new perspectives on the topic or elevate their investment in the discussion. There was a level of humility expressed in the recognition that the students could often have greater knowledge on specific topics, and they deferred to that experience, and felt they learned from their students in each course they taught. Most acknowledged that their high level of presence at the beginning of a course created a momentum in the discussions; however, when they recognized that students took responsibility and were engaging with each other, they stepped back from the participation and focused on providing feedback on assignments but kept a watchful eye on participation being ready to jump back in if interaction decreased significantly. However, when they did participate in forums in later parts of the course, they described a higher level of interaction, with the intent of challenging or advancing their students' participation beyond mere posts. Most expressed a sense of pride in the ownership that their students took in the forums.

\section{Intentions of Instructors}

The intentions behind the pedagogical choices revealed by the participants related to ensuring that an active participation in the learning process occurred in the courses taught by the subjects, based on a recognition of the role the instructor serves while interacting with students in an authentic way. The actions that primarily supported the fulfillment of these intentions were identified to be: forming authentic relationships with students, building rapport, and setting and reinforcing expectations. The intentions of instructors echoed the interpretation they had of teaching presence, in which being responsive to student needs and being available to support and guide them established the role of the instructor as a facilitator of learning.

\section{Influence on Academic Climate and Intellectual Curiosity}

The analysis of the collective case revealed that by setting and reinforcing expectations for performance and participation, instructors established an academic tone of expected engagement, thereby supporting their intention of creating engagement and interaction that supported learning. Instructors intentionally relayed the message to students that they had a genuine interest in sharing knowledge and experiences that had relevance to the students. Through their actions, instructors set the expectation of a shared responsibility for learning that relied on engagement and interaction among the student peers. As a collegial relationship was formed, instructors created an active interest in the course topics which not only increased engagement in the learning process, but inspired individual investigation and inquiry that contributed to group learning as well as advancement of personal learning related to the topics of the course. These insights suggest that the ability to understand what is relevant to students and encourages them to delve deeper academically has its roots in the authentic relationships formed between instructor and student, providing the instructor with the insight as to what motivates and ignites students' curiosity. 


\section{Conclusions and Future Research}

The findings of this study provide insight into the overarching question that guided this study, how instructors establish teaching presence and inspire intellectual curiosity in their courses. Overall, the collective case revealed an active interest and passion for teaching that encouraged student participation and engagement and inspired a shared responsibility for the learning process, supporting Akyol and Garrison's (2011) assertion that teaching presence becomes a shared responsibility of both instructor and students, with student participation being highly influenced by the instructor's actions. The findings show that the common goal of learning shared by instructor and student had its foundations in the creation of authentic relationships between instructor and students.

The results indicate that actions that produce a high level of visibility must be accompanied with intentional social and cognitive practices that are valued by adult learners. Pedagogical approaches must have both social and cognitive dimensions in order to establish an active teaching presence. As the intentions behind these pedagogical choices were explored, instructors repeatedly described the decision to take a proactive stance in establishing relationships with students to successfully gain the trust and respect that forms the foundation of authentic relationships. This intention of interaction extends beyond a welcome letter, and solicits students' participation by providing relevant connections to the course topics at the very start of the course. The instructor sets an academic tone through his or her own actions and enthusiasm for the course, conveying a genuine interest in supporting the student through the learning process (Costley, 2015; KyeiBlankson et al., 2016). By communicating an expectation of shared responsibility and common learning goals, the instructor creates an environment for open exchange of information and inspires collaboration among student peers.

As interpreted from the accounts of the instructors, a key action that influenced the intellectual climate of a course was to create an inclusive and equitable learning environment. When contributions of students are not only encouraged, but respected and acknowledged as valuable, students are inspired to independently explore concepts related to the course in order to share the knowledge with peers or apply that knowledge to their own circumstances. Key to creating this environment is an instructor's willingness to share the responsibility of teaching, not just learning, promoting collaborative and engaging interaction that develops critical thinking (Costley, 2015; Kyei-Blankson, Ntuli, \& Donnelly, 2016). This reciprocal relationship in the teaching and learning process, whereby instructors are confident enough to defer to students' experiences and knowledge, creates a teaching presence that is a shared agency in intellectual development that extends beyond the individual instructor (Tsiotakis \& Jimoyiannis, 2016).

The essence of "presence" is a mindset for extending activity between student, instructor and content. The presence mindset is not one-dimensional; its multi-dimensional nature extends the reach 'beyond just being there'. Emerging from this research are opportunities for future research that will broaden the understanding of the nature of teaching presence and the practices used to establish it in the online classroom. As this research included data from student evaluations of faculty/instruction quality from selected archived courses, we recognize that student evaluations do not necessarily represent or translate to student performance. Thus, future research could also investigate the nature of teaching presence practices and shared agency that lead to evidence of student performance. In addition, the selection of a research site where all instructors utilized the same technology and the same instructional delivery procedures eliminated a level of variability that exists in other institutional settings, but confined the generalizability of the findings. 
Specifically a suggested area of research is to determine whether experienced instructors in different educational settings using both prescribed and unstructured delivery approaches express similar attitudes and practices. Research could also extend inquiry to understand the presence mindset among faculty given varying demographics (i.e., academic disciplines, online teaching experience, teaching experience in general). For example, faculty teaching in the STEM fields may not have formal training in facilitating effective online and blended learning practices. Studies such as these suggested may provide external validity to the findings of this study and increase the generalizability to contexts beyond the structured delivery environment. 


\section{References}

Afolabi, R.O. (2016). Emphasizing instructor presence in digital learning environments. In S. D'Agustino (Ed.), Creating teacher immediacy in online learning environments (pp.3754). Hershey, PA: IGI Global. doi:10.4018/978-1-4666-9995-3.ch003

Akyol, Z., \& Garrison, D.R. (2011). Understanding cognitive presence in online and blended community of inquiry: Assessing outcomes and processes of deep approaches to learning. British Journal of Educational Technology, 42(2), 233-250. doi: 10.1111/j.14678535.2009.01029.x

Anderson, T. \& Dron, J. (2011). Three generations of distance education pedagogy. International Review of Research in Open and Distance Learning, 12(3), 80-97.

Arbaugh, J.B. (2013). Does academic discipline moderate CoI course outcomes relationships in online MBA courses? Internet and Higher Education, 17, 16-28.

doi: 10.1016/j.iheduc.2012.10.002

Arbaugh, J.B., \& Hwang, A. (2006). Does "teaching presence" exist in online MBA courses? The Internet and Higher Education, 9(1), 9-21.

Baran, E., Correia, A.P., \& Thompson, A.D. (2013). Tracing successful online teaching in higher education: Voices of exemplary online teachers. Teachers College Record, 115(3), 1-41.

Bawa, P. (2016). Retention in online courses: Exploring issues and solutions - A literature review. SAGE Open, January-March 2016, 1-11. doi: 10.1177/2158244015621777

Baxter, P., \& Jack, S. (2008). Qualitative case study methodology: Study design and implementation for novice researchers. The Qualitative Report, 13(4), 544-559.

Bondi, S., Daher, T., Holland, A., Smith, A.R., \& Dam, S. (2016). Learning through personal connections: Cogenerative dialogues in synchronous virtual spaces. Teaching in Higher Education, 21(3), 301-312. doi: 10.1080/13562517.2016.1141288

Bowden, R. (2012). Online graduate education: developing scholars through asynchronous discussion. International Journal of Teaching and Learning in Higher Education, 24(1), 52-64.

Brock, S. \& Abel, A.L. (2012). Creating a Learning Climate for the $21^{\text {st }}$ Century. Transformative Dialogues: Teaching and Learning Journal, 5(3), 1-16.

Chenail, R.J. (2012). Conducting qualitative data analysis: qualitative data analysis as a metaphoric process. The Qualitative Report, 17(1), 248-253.

Cho, M.H., \& Kim, B.J. (2013). Students' self-regulation for interaction with others in online learning environments. Internet and Higher Education, 17, 69-75. doi: 10.1016/j.iheduc,2012.11.001 
Costley, J. (2015). The effects of three types of instructor posting on critical thinking and social presence: No posting, facilitating discourse, and direct instruction. International Journal of Learning, Teaching and Educational Research, 12(2), 26-47.

Cox-Davenport, R.A. (2010). A grounded theory approach to faculty's perspective and patterns on online social presence. Available from ProQuest Dissertation and Theses database. (UMI No. 3412363)

Cox-Davenport, R.A. (2014). A grounded theory of faculty's use of humanization to create online course climate. Journal of Holistic Nursing, 32(1), 16-24. doi: $10.1177 / 0898010113499201$

Creswell, J.W. (2013). Research Design: Qualitative, Quantitative and Mixed Method Approaches (3rd ed.). Thousand Oaks, CA: Sage Publications, Inc.

Duncan, H.E., \& Barnett, J. (2010). Experiencing online pedagogy: A Canadian case study. Teaching Education, 21(3), 247-262. doi: 10.1080/10476210903480340

Ekmekci, O. (2013). Being there: Establishing presence in an online learning environment. Higher Education Studies, 3(1), 29-38. doi: 10.5539/hes.v3n1p29

Friesen, N. (2009). Hermeneutic phenomenology: Experiential evidence in e-learning. In J. L.Kinchloe \& S. R. Steinberg (Eds.), Re-thinking e-learning research: Foundations, methods, and practices (pp. 119-148). New York, NY: Peter Lang Publishing Inc.

Garrison, D.R., \& Akyol, Z. (2013). Toward the development of a metacognition construct for communities of inquiry. The Internet and Higher Education, 17, 84-89. doi: 10.1016/j.iheduc.2012.11.005

Garrison, D.R., Anderson, T., \& Archer.W. (1999). Critical inquiry in a text-based environment: Computer conferencing in higher education. The Internet and Higher Education, 2(2-3), 87-105. doi:10.1016/S1096-7516(00)00016-6

Garrison, D.R., Anderson, T., \& Archer, W. (2001). Critical thinking, cognitive presence, and computer conferencing in distance education. The American Journal of Distance Education, 15(1), 7 -23. doi:10.1080/08923640109527071

Garrison, D.R., \& Arbaugh, J.B. (2007). Researching the community of inquiry framework: Review, issues, and future directions. Internet and Higher Education, 10, 157-172. doi: 10.1016/j.iheduc.2007.04.001

Garrison, D.R., Cleveland-Innes, M., \& Fung, T.S. (2010). Exploring causal relationships among teaching, cognitive, and social presence: Student perceptions of the community of inquiry framework. Internet \& Higher Education, 13(1-2), 31-36. doi:10.1016/j.iheduc.2009.10.002 
Hung, M.L., \& Chou, C. (2015). Students' perceptions of instructors' roles in blended and online learning environments: A comparative study. Computers \& Education, 81, 315-325. Doi: 10.1016/j.compedu.2014.10.022

Joo, Y.J., Joung, S., \& Kim, E.K. (2013). Structural relationships among e-learners' sense of presence, usage, flow, satisfaction, and persistence. Educational Technology \& Society, $16(2), 310-324$.

Junk, V., Deringer, N., \& Junk, W. (2011). Techniques to engage the online learner. Research in Higher Education Journal, 10, 1-15.

Kaufmann, R., Sellnow, D.D., \& Frisby, B.N. (2015). The development and validation of the online learning climate scale(OLCS), Communication Education, 1-15. doi: 10.1080/03634523.2015.1101778

Kidder, L. C. (2015). The Multifaceted Endeavor of Online Teaching: The Need for a New Lens. In B. Hokanson, G. Clinton, \& M. W. Tracey (Eds.), The Design of the Learning Experience: Creating the Future of Educational Technology, pp. 77-91. Switzerland: Springer International. doi: 10.1007/978-3-319-16504-2_6

Kyei-Blankson, L., Ntuli, E., \& Donnelly, H. (2016). Establishing the importance of interaction and presence to student learning in online environments. World Journal of Educational Research, 3(1), 48-65.

Lehman, R.M., \& Conceição, S.C.O. (2010). Using a design framework to create a s sense of presence. Paper presented at the $26^{\text {th }}$ Annual Conference on Distance teaching \& Learning, Madison, WI, retrieved from http://www.uwex.edu/disted/conference

March, L. \& Lee, J.R. (2016). Teaching teachers to teach online: How to implement an evidencebased approach to training faculty. In Proceedings of Society for Information Technology \& Teacher Education International Conference 2016 (pp. 714-720). Chesapeake, VA: Association for the Advancement of Computing in Education (AACE).

Niess, M., \& Gillow-Wiles, H. (2013). Developing asynchronous online courses: key instructional strategies in a social metacognitive constructivist learning trajectory. The Journal of Distance Education/Revue de l'Education á Distance, 27(1).

Orcutt, J. M. (2016). Teaching presence and intellectual climate in a structured online learning environment (Order No. 10159552). Available from Dissertations \& Theses @ Nova Southeastern University. (1825399597). Retrieved from http://search.proquest.com.ezproxylocal.library.nova.edu/docview/1825399597?accounti $\mathrm{d}=6579$

Ravenna, G. (2012). The effects of increased workloads on online instruction. International Journal of Education, 4(4), 125-133. Doi; 10.5296/ije.v4i4.2269 
Rovai, A.P. (2007). Facilitating online discussion effectively. Internet and Higher Education, 10, 77-88. doi:10.1016/j.iheduc.2006.10.001

Seidman, I. (2006). Interviewing as qualitative research: A guide for researchers in education and the social sciences, $3^{\text {rd }}$ ed. New York, NY: Teachers College, Columbia University.

Shea, P. \& Bidjerano, T. (2010). Learning presence: Towards a theory of self-efficacy, selfregulation, and the development of communities of inquiry in online and blended learning environments. Computers \& Education, 55, 1721-1731. doi:10.1016/j.compedu.2010.07.017

Shea, P., Vickers, J., \& Hayes, S. (2010). Online instructional effort measured through the lens of teaching presence in the community of inquiry framework: A re-examination of measures and approach. International Review of Research in Open and Distance Learning, 11(3), $127-154$.

Smith, J.A., Flowers, P., \& Larkin, M. (2009). Interpretative phenomenological analysis: Theory, method and research. London, UK: Sage Publications Limited.

Southcombe, A. Fulop, L., Carter, G. \& Cavanagh, J. (2015). Building commitment: An examination of learning climate congruence and the affective commitment of academics in an Australian university. Journal of Further and Higher Education, 39(5), 733-757. doi: $10.1080 / 0309877 X .2013 .869566$

Stake, R.E. (1995). The art of case study research. Los Angeles, CA: Sage Publications.

Stake, R.E. (2006) Multiple case study analysis. New York, NY: The Guilford Press.

Tsoitakis, P., \& Jimoyiannis, A. (2016). Critical factors towards analyzing teachers' presence in on-line learning communities. Internet \& Higher Education, 28, 45-58. doi: 10.1016/j.iheduc.2015.09.002

Willis, J.W. (2008). Qualitative research methods in education and educational technology. Charlotte, NC: Information Age Publishing, Inc.

Xin, C. (2012). A critique of the community of inquiry framework. The Journal of Distance Education, 26(1). Retrieved from http://www.jofde.ca/index.php/jde/article/viewArticle/755/1333

Yang, J.C., Quadir, B., Chen, N.S., \& Miao, Q. (2016). Effects of online presence on learning performance in a blog-based online course. Internet \& Higher Education, 30, 11-20. doi: 10.1016/j.iheduc.2016.04.002

Yin, R.K. (2014). Case study research: Design and methods (5th ed.) Los Angeles, CA: Sage Publications, Inc. 